\title{
Pendampingan Komunitas Sekolah melalui Kegiatan Vertical Garden untuk Mewujudkan Sekolah Dasar berbasis Lingkungan di SDN 34 Kota Ternate Maluku Utara
}

\author{
Abdulrasyid Tolangara, Rohima Wahyu Ningrum \\ ${ }^{1,2}$ Universitas Khairun Ternate Maluku Utara \\ rtolangara@yahoo.com; ima.geolive@gmail.com
}

\begin{abstract}
School yard is the most appropriate learning media to support learning creativity for learners. The narrow use of school yard has not been well implemented, so that the students' ignorance towards the environment is closely related to the decreasing environmental quality in schools. To improve the quality of education and learning achievement of learners about environmental knowledge, school can provide a direct understanding to learners about the environment by applying the concept of vertical garden in the yard of the school. Vertical concept of this garden becomes an alternative way in getting around the yard or narrow land. The school plays an important role in this devotion program at the time of making the garden vertical garden, where the school proposes the implementation of maintenance activities and planting new plant species in the annual plan of SDN 34 Kota Ternate. Socialization and workshops that have been done with the school together with community service team, it can provide an early description of the use of a narrow school yard by applying the garden vertical garden. Another target of this program is that students and teachers feel the benefits of this school park in classroom learning, so that they can apply the concept of farming obtained for the home.
\end{abstract}

Keyword: Garden vertical garden, environment, school yard.

\section{Pendahuluan}

Pekarangan sekolah merupakan media belajar yang paling tepat untuk menunjang kreativitas belajar bagi peserta didik. Dimana bisa dimanfaatkan untuk peningkatan pengetahuan tentang lingkungan. Dari banyak sekolah yang memiliki pekarangan sekolah, lebih banyak dijadikan lapangan olahraga sehingga mengurangi area hijau di sekolah. Wadah pekarangan sekolah yang tidak memadai untuk belajar tentang lingkungan seperti kegiatan penanaman pohon dan bercocok tanam, akan membuat kesadaran lingkungan peserta didik menjadi rendah.

Pemanfaatan lahan yang kecil di pekarangan sekolah untuk menanam tanaman harus diajarkan kepada peserta didik di sekolah dasar sejak dini. Konsep yang digunakan merupakan hasil kreasi inovatif untuk menumbuhkan tanaman tanpa menggunakan tanah sebagai media pertumbuhan. Tanaman dan elemen tanam lainnya yang dibuat dalam sebuah bidang tegak, biasa disebut Vertical Garden. Vertical garden adalah sebuah konsep taman vertikal yang dikembangkan oleh Patrick Blanc dari Perancis. Hal ini dilakukan untuk menumbuhkan kesadaran generasi muda

Volume 2, Number 1, Mei 2018| 62 Pendampingan Komunitas Sekolah melalui Kegiatan Vertical Garden untuk Mewujudkan Sekolah Dasar berbasis Lingkungan di SDN 34 Kota Ternate Maluku Utara 
akan kepedulian terhadap lingkungan semakin meningkat. Hasil yang diperoleh dari pemanfaatan pekarangan sekolah ini diharapkan bisa bermanfaat bagi warga sekolah dan sekitarnya.

Berdasarkan observasi awal di Sekolah Dasar yang berada di Kota Ternate, ada beberapa sekolah yang memiliki pekarangan yang sempit dan tidak dimanfaatkan untuk pengembangan pengetahuan tentang lingkungan. Salah satunya adalah Sekolah Dasar Negeri 34 Kota Ternate yang mempunyai pekarangan sekolah berukuran 5 x $5 \mathrm{~m}$. Pekarangan sekolah hanya dimanfaatkan untuk peserta didik bermain, upacara dan olahraga. Sekolah ini hanya ditanami tanaman hias, dan belum ada kegiatan bercocok tanam dikarenakan kurangnya pekarangan sekolah. Terlihat, pada saat wawancara dengan beberapa peserta didik, terdapat pemahaman yang kurang tentang lingkungan. Hal inilah yang membuat kreativitas peserta didik menurun.

Selin itu, kondisi sekolah hingga saat ini belum ada upaya peningkatan kesadaran peserta didik mengenai lingkungan, dikarenakan area sekolah yang tidak didukung untuk dilakukannya kegiatan lingkungan, seperti penanaman pohon dan bercocok tanam. Walaupun ada beberapa kegiatan lingkungan lain seperti kerja bakti sekolah, namun dirasa masih kurang cukup guna mencapai sasaran ke peserta didik.

Sehubungan dengan masalah yang ada disekolah inilah, maka kegiatan program pengabdian kepada masyarakat menawarkan untuk menerapkan konsep vertical garden dengan memanfaatkan pekarangan sekolah yang sempit, sehingga dapat mewujudkan kesadaran akan lingkungan kepada peserta didik sejak dini. Kegiatan ini dilakukan dengan 2 (dua) contoh tanaman, yakni tanaman sayur dan tanaman hias. Ini yang diharapkan akan dapat menjadi pelajaran berupa pengalaman kepada peserta didik dan warga sekolah yang terlibat agar bisa menambah pengetahuan tentang pemanfaatan pekarangan atau lahan yang sempit. Harapannya, bisa diaplikasikan dalam waktu yang panjang dan dibagikan di warga sekitar sekolah. Melalui pengabdian ini bertujuan untuk memberikan pemahaman peserta didik secara langsung mengenai lingkungan dan penerapannya dengan konsep Vertical Garden. Sehingga peserta didik memiliki pembelajaran dan pengalaman untuk berlatih menanam tanaman dengan cara kreatif dan atraktif Peran mitra dalam kegiatan ini agar dapat mandiri dalam pengelolaan dan pemanfaatan pekarangan atau lahan sempit di sekolah maupun tempat tinggal.

\section{Metode}

Adapun metode pengabdian masyarakat ini menggunakan community development dengan melakukan beberapa rangkaian tahapan, diantaranya: tahap persiapan, tahap, pengenalan, tahap 
pelaksanaan, pemantauan tim ke lokasi mitra, dan tahap evaluasi.

\section{Tahap Persiapan}

Perencanaan program pengabdian mandiri ini dimulai dengan melakukan survei lokasi di SDN 34 Kota Ternate dan melakukan wawancara kepada pihak sekolah yang terletak di jalan Bali Bunga Kel. Tabona, Kecamatan Kota Ternate Selatan, untuk memperoleh data primer mengenai kondisi sekolah dan pemanfaatan pekarangan sekolah. Selanjutnya dilakukan pengukuran luas pekarangan sekolah tersebut. Dari hasil observasi awal maka dapat dilakukan penyusunan proposal pengabdian masyarakat.

\section{Tahap Pengenalan}

Dalam tahapan pengenalan berupa sosialisasi kepada peserta didik dan warga sekolah di SDN 34 Kota Ternate dengan maksud memberikan pemahaman terlebih dahulu mengenai pengetahuan tentang lingkungan hidup dan latar belakang pelaksanaan kegiatan konsep Vertical Garden. Warga sekolah yang dilibatkan dalam kegiatan ini adalah peserta didik 2 (dua) kelas, yakni kelas 5 dan kelas 6 dan melibatkan seluruh guru di sekolah tersebut.

\section{Tahap Pelaksanaan}

Dalam pelaksanaan penerapan vertical garden kepada peserta didik dan warga sekolah yang terlibat adalah dengan cara pembentukan kelompok kerja (workshop). Selain itu, diberikan sedikit bekal pengetahuan tentang vertical garden, alat dan bahan yang digunakan dan metode pengerjaannya. Pemahaman dan keterampilan yang diharapkan dari program ini dapat digunakan sebagai bekal dalam pembuatan vertical garden di pekarangan SDN 34 Kota Ternate dan sekitarnya di masa yang akan datang, sehingga diharapkan warga sekolah dapat menangani permasalahan mengenai lingkungan dengan penerapan vertical garden. Kemudian persiapan kerja yang dilakukan berupa: menyiapkan media tanam, pupuk dan bibit. Setelah media tanam disiapkan, maka langkah berikutnya adalah melakukan penanaman, disini ada dua tanaman yang di tanam, yaitu tanaman sayur dan tanaman hias.

\section{Pemantauan tim ke Lokasi Mitra}

Setelah dilakukan penanaman, maka dilakukan pemantauan terhadap keberhasilan kegiatan dimaksud seminggu sekali di lokasi SD 34 Kota Ternate, pemantauan tersebut bermaksud untuk member gambaran keberhasilan tanaman tersebut. 


\section{Tahap Evaluasi}

Sebagai bahan evaluasi dari kegiatan pengabdian masyarakat ini maka peserta didik akan diberikan kuisioner sebelum dan sesudah dilaksanakan kegiatan pengabdian mandiri, dan dijadikan parameter keberhasilan dari kegiatan dimaksud. Kemudian hasil evaluasi tersebut sebagai bahan pertimbangan dalam penyusunan laporan akhir.

\section{Hasil dan Diskusi}

\section{Gambaran Lokasi Pengabdian}

Lokasi pengabdian berada di SDN 34 Kota Ternate dengan jumlah siswa tiga tahun terakhir dengan rata-rata 328 siswa yang terbagi atas 6 kelas. Ruang terbuka pada sekolah ini hanya terdapat lapangan olahraga yang biasa digunakan sebagai lapangan upacara dan untuk taman sekolah yang belum tersedia. Sekolah ini hanya ditanami tanaman hias, dan belum ada kegiatan bercocok tanam lain dikarenakan perkarangan sekolah yang sempit, sehingga belum dapat memanfaatkan taman sekolah sebagai sarana edukasi seperti pengembangan pengetahuan tentang lingkungan. Pada saat observasi awal kepada beberapa peserta didik, dimana terdapat pemahaman yang kurang tentang lingkungan khususnya jenis tanaman.


Gambar 1. Kondisi pekarangan SDN 34 Kota Ternate

\section{Permasalahan dan Solusi}

Permasalahan umum yang tampak pada lokasi sekolah adalah perkarangan sekolah yang sempit, sehingga untuk penataan vegetasi yang kurang rapi, taman sekolah yang digunakan sebagai sarana edukasi siswa belum tersedia, dan kurangnya vegetasi sehingga sekolah terkesan kering dan gersang. Perkarangan sekolah merupakan bangunan utama yang berfungsi sebagai edukasi bagi siswa. Taman sekolah juga dirasa cukup penting karena dengan banyaknya tanaman akan membuat linglungan sekolah menjadi nyaman, selain itu bisa sebagai sarana edukasi untuk mengenalkan jenis tanaman dan cara perawatannya kepada siswa. Adapun program pemerintah berupa lomba lingkungan hidup atau green school festival sebagai media identifikasi kekurangan taman, siswa

Volume 2, Number 1, Mei 2018| 65 Pendampingan Komunitas Sekolah melalui Kegiatan Vertical Garden untuk Mewujudkan Sekolah Dasar berbasis Lingkungan di SDN 34 Kota Ternate Maluku Utara 
dilibatkan untuk penyelesaian masalah.

Solusi yang ditawarkan pada sekolah ini adalah penerapan taman vertical garden untuk pekarangan sekolah yang sempit atau kecil. Metode yang digunakan untuk mengajarkan siswa-siswi memanfaatkan lahan yang kecil dipekarangan sekolah dengan menanam beberapa jenis tanaman yang berguna dan terkesan indah. Penerapan taman vertical garden diharapkan dapat membangun dan meningkatkan kesadaran generasi muda akan kepedulian terhadap lingkungan dan ikut andil dalam penghijauan di lingkungan rumah. Peduli lingkungan merupakan sikap dan tindakan yang berupaya mencegah kerusakan pada lingkungan alam di sekitarnya, dan mengembangkan upayaupaya untuk memperbaiki kerusakan alam yang sudah terjadi.

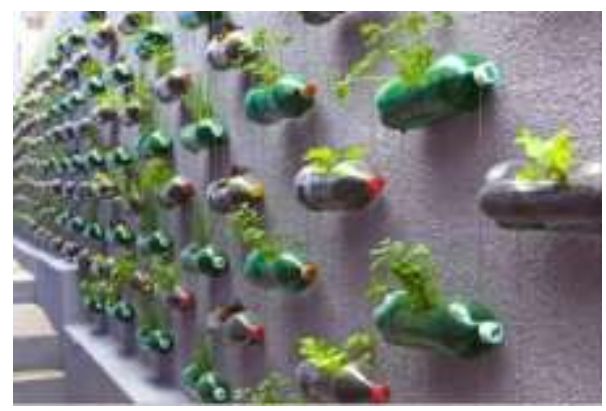

Gambar 2. Model Vertical Garden

\section{Pelaksanaan Kegiatan Pengabdian}

Program pengabdian kepada masyarakat ini dilaksanakan selama 4 bulan dengan beberapa perencanaan kegiatan sebagai berikut:

\section{Tahap Persiapan}

a. Data awal

Perencanaan program pengabdian mandiri ini dimulai dengan melakukan survei lokasi di SDN 34 Kota Ternate dan melakukan wawancara kepada pihak sekolah yang terletak di jalan Bali Bunga Kel. Tabona, Kecamatan Kota Ternate Selatan, untuk memperoleh data primer mengenai kondisi sekolah dan pemanfaatan pekarangan sekolah tersebut. Selanjutnya dilakukan juga pengukuran luas pekarangan sekolah tersebut. Dari hasil observasi awal maka dapat dilakukan penyusunan proposal pengabdian masyarakat.

b. Pengukuran pekarangan sekolah

Pengukuran perkarangan sekolah dilakukan untuk mengetahui layak atau tidaknya pekarangan sekolah itu digunakan sebagai sarana edukasi. Berdasarkan pengamatan dan wawancara kepada warga sekolah diketahui bahwa perlunya suatu ruang taman yang berfungsi mewadahi semua aktivitas. Taman sekolah memiliki fungsi primer sebagai sarana edukasi dimana memerlukan

Volume 2, Number 1, Mei 2018|66 Pendampingan Komunitas Sekolah melalui Kegiatan Vertical Garden untuk Mewujudkan Sekolah Dasar berbasis Lingkungan di SDN 34 Kota Ternate Maluku Utara 


\section{ENGAGEMENT}

Qurnal Pengabdian Kepada Masyarakat

ISSN: 2579-8375 (Print)

ISSN: 2579-8391 (Online)
This work is licensed under a Creative Commons

Attribution-ShareAlike 4.0 International License.

area dengan jenis ragam tanaman (tanaman hias, dan toga) serta vertikultur untuk pembelajaran siswa. Ruang terbuka seperti pekarangan sekolah yang berupa lapangan biasan yang digunakan siswa bermain dengan berlari dan menjalin sosial dengan teman-temannya, dan kegiatan mengeksplorasi kreativitas (Setyabudi,2017).
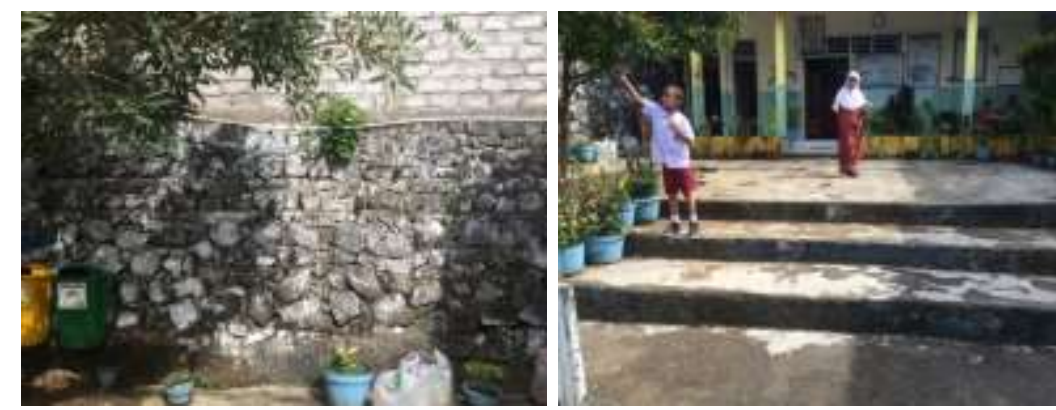

Gambar 3. Pengukuran rencana letak, pembuatan taman vertical garden

Letak pembuatan taman vertical garden terpisah dengan pekarangan sekolah namun tidak jauh. Ini dilakukan supaya tidak menggangu aktivitas siswa pada waktu jam istirahat yang biasanya bermain di pekarangan sekolah.

\section{Tahap Pengenalan}

a. Sosialisasi kegiatan pengabdian ke pihak sekolah

Dalam tahapan ini, dilakukan pengenalan berupa sosialisasi kepada peserta didik dan warga sekolah di SDN 34 Kota Ternate dilakukan untuk memberikan pemahaman terlebih dahulu mengenai pengetahuan tentang lingkungan hidup dan latar belakang pelaksanaan kegiatan konsep Vertical Garden di sekolah.
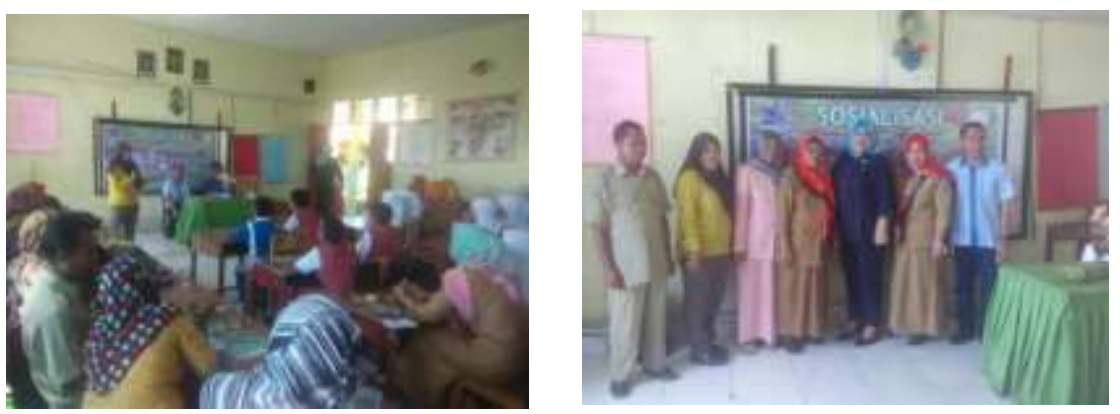

Gambar 4. Sosialisasi kegiatan pengabdian kepada masyarakat di SDN 34 Kota Ternate

Volume 2, Number 1, Mei 2018|67

Pendampingan Komunitas Sekolah melalui Kegiatan Vertical Garden untuk Mewujudkan Sekolah Dasar berbasis Lingkungan di SDN 34 Kota Ternate Maluku Utara 


\section{ENGAGEMENT}

Jurnal Pengabdian Kepada Masyarakat

ISSN: 2579-8375 (Print)

ISSN: 2579-8391 (Online)
This work is licensed under a Creative Commons Attribution-ShareAlike 4.0 International License.

b. Persiapan bahan dan alat yang digunakan

Persiapan bahan dan alat yang digunakan melibatkan warga sekolah. Pekerjaan persiapan ini merupakan kegiatan awal dalam mempersiapkan taman vertical garden. Bahan berupa botol dipersiapkan sekitar 2 minggu untuk proses pembersihan, pembolongan botol, pengecatan botol dan pengeringan guna menghasilkan botol yang berkualitas baik.
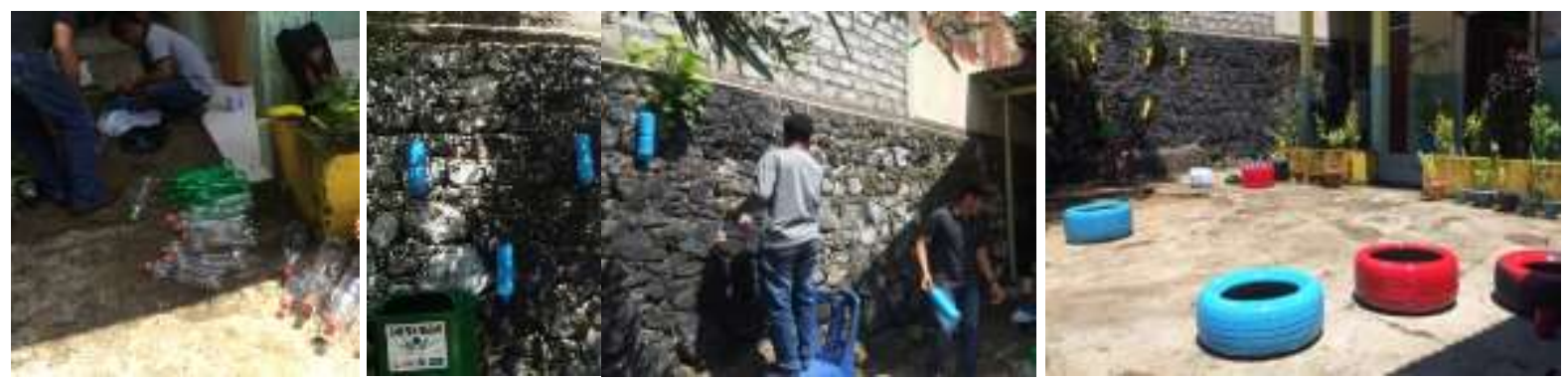

Gambar 5. Kegiatan persiapan alat dan bahan

\section{Tahap Pelaksanaan}

a. Pembentukan kelompok kerja (Workshop)

Dalam pelaksanaan penerapan konsep vertical garden kepada peserta didik dan warga sekolah yang terlibat adalah dengan cara pembentukan kelompok kerja (workshop) dalam pelaksanaannya. Selain itu, diberikan sedikit bekal pengetahuan tentang vertical garden, alat dan bahan yang digunakan dan metode pengerjaannya. Pemahaman dan keterampilan yang diharapkan dari program ini dapat digunakan sebagai bekal dalam pembuatan vertical garden di pekarangan SDN 34 Kota Ternate dan sekitarnya untuk di masa yang akan datang, sehingga diharapkan warga sekolah dapat menangani permasalahan mengenai lingkungan dengan penerapan konsep vertical garden. Kemudian persiapan kerja yang dilakukan pertama adalah menyiapkan media tanam, pupuk dan bibit. Setelah media tanam telah siap, maka langkah kedua adalah melakukan penanaman, disini ada dua tanaman yang di tanam, yaitu tanaman sayur dan tanaman hias.
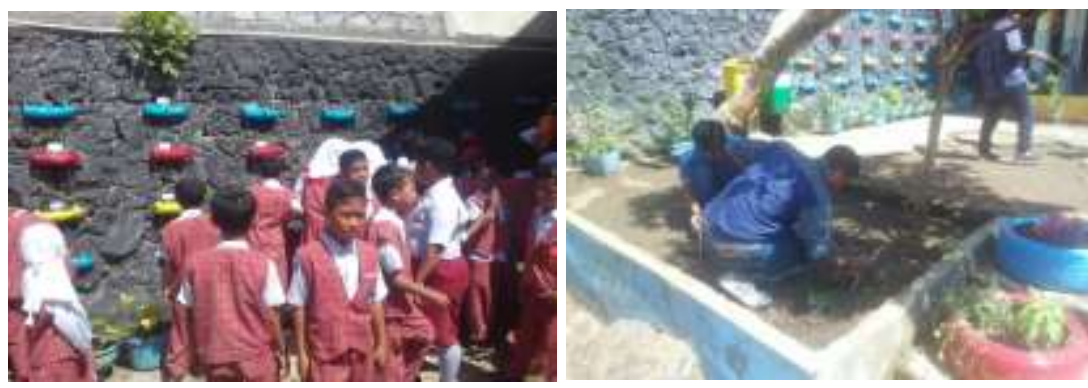

Gambar 6. Kegiatan pembentukan kelompok untuk persiapan kerja

Volume 2, Number 1, Mei 2018| 68

Pendampingan Komunitas Sekolah melalui Kegiatan Vertical Garden untuk Mewujudkan Sekolah Dasar berbasis Lingkungan di SDN 34 Kota Ternate Maluku Utara 


\section{ENGAGEMENT}

Gurnal Pengabdian Kepada Masyarakat

ISSN: 2579-8375 (Print)

ISSN: 2579-8391 (Online)

b. Pembuatan taman vertical garden
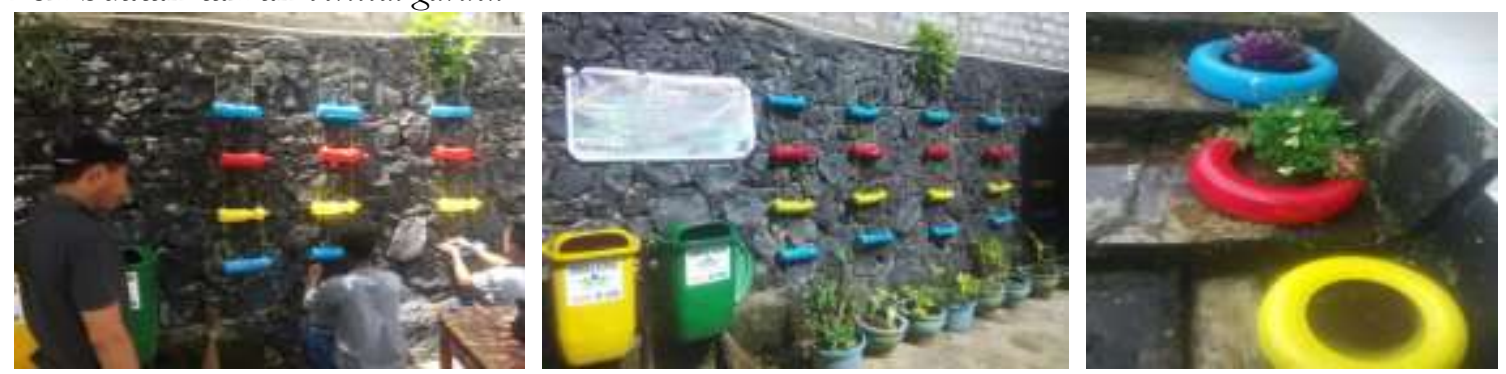

Gambar 7. Taman Vertical Garden

c. Pemasangan label setiap jenis tanaman

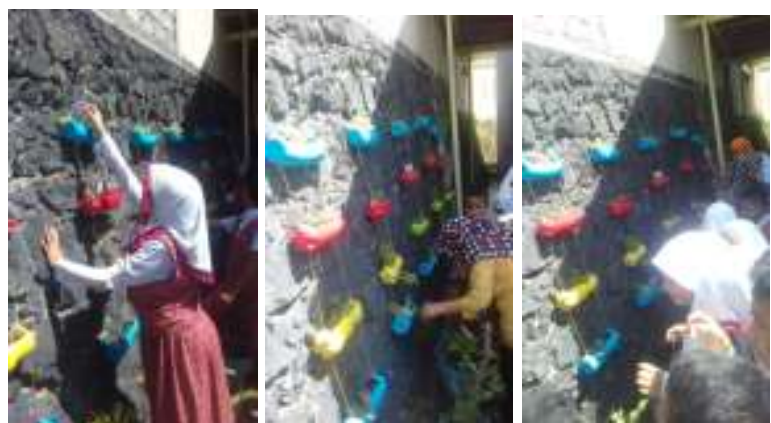

Gambar 8. Kegiatan pemasangan label nama pada tiap jenis tanaman

\section{Kesimpulan}

Dari program pengabdian masyarakat ini, maka dapat disimpulkan bahwa pihak sekolah memiliki penting dalam pengembangan program pengabdian pembuatan taman vertical garden, dimana pihak sekolah mengusulkan pelaksanaan kegiatan perawatan dan penanaman jenis tanaman baru dalam rencana tahunan SDN 34 Kota Ternate. Melalui sosialisasi dan workshop yang telah dilakukan bersama pihak sekolah bersama tim pengabdian masyarakat Unkhair dapat memberikan gambaran awal tentang pemanfaatan pekarangan sekolah yang sempit dengan menerapkan taman vertical garden. Dengan terwuudnya Taman vertical garden, maka taman tersebut menjadi sarana edukasi pengembangan pengetahuan peserta didik tentang lingkungan hidup, sehingga peserta didik dan guru merasakan manfaat dari taman sekolah ini sebagai salah satu media pendukung pembelajaran di kelas dalam konsep bercocok tanam untuk diaplikasikan di rumah.

\section{Daftar Referensi}

Rakhmawati,D., dkk. 2016. Peran Program Adiwiyata Dalam Pengembangan Karakter Peduli Lingkungan Siswa: Studi Kasus di SMK Negeri 2 Semarang. Unnes Science Education Journal. Semarang Setyabudi, I., Nuraini, Alfian, R., Nailufar, B., 2017. Konsep Taman Edukasi pada Sekolah Dasar di Kota Malang (Studi Kasus: SDN Lowokwaru 3 Malang). Jurnal RUAS, Volume 15 No 1, Juni 2017, ISSN 1693-3702

Volume 2, Number 1, Mei 2018|69 Pendampingan Komunitas Sekolah melalui Kegiatan Vertical Garden untuk Mewujudkan Sekolah Dasar berbasis Lingkungan di SDN 34 Kota Ternate Maluku Utara 
Sri Narwanti. 2011. Pendidikan Karakter Pengintegrasian 18 Nilai Pembentuk Karakter dalam Mata Pelajaran. Yogyakarta: Familia

Surat Kesepakatan Kementerian Lingkungan Hidup Keputusan 07/MENLH/06/2005 dan Departemen Pendidikan Nasional Nomor: dan Nomor: 05/VI/KB2005 tentang pembinaan dan pengembangan pendidikan lingkungan bidup. 